\title{
THE MAINTENANCE OF PER-OPERATIVE MYDRIASIS IN PHACOEMULSIFICATION WITH TOPICAL DICLOFENAC SODIUM
}

\author{
R. J. ANTCLIFF ${ }^{1}$ and D. R. TREW \\ Sidcup and Orpington
}

\begin{abstract}
SUMMARY
Purpose: To determine whether the use of topical diclofenac sodium (diclofenac) pre-operatively improves the maintenance of per-operative mydriasis, in conjunction with irrigating solutions containing adrenaline.

Methods: Sixty-four consecutive patients undergoing phacoemulsification were randomised to receive either diclofenac or no diclofenac in conjunction with cyclopentolate $1 \%$ and phenylephrine $10 \%$ pre-operatively. They subsequently underwent routine phacoemulsification by one consultant surgeon. Irrigating solutions of balanced salt solution contained adrenaline 1:10 ${ }^{6}$. Pupil diameters were measured pre-sclerostomy, postphacoemulsification, post-irrigation/aspiration and on day 1 post-operatively. These were then compared by Student's $t$-test.

Results: The two groups were statistically similar in age and sex. The mean pre-sclerostomy pupillary diameters were $8.1 \mathrm{~mm}$ in both groups. The mean post-phacoemulsification diameters were $7.6 \mathrm{~mm}$ in those receiving diclofenac and $7.2 \mathrm{~mm}$ in those not $(p=0.03)$. The mean diameters after infusion/aspiration were $7.7 \mathrm{~mm}$ in those receiving diclofenac and $7.1 \mathrm{~mm}$ in those not $(p=0.008)$. The mean pupillary diameters on day 1 were $5.3 \mathrm{~mm}$ in those receiving diclofenac and $4.6 \mathrm{~mm}$ in those not $(p=0.003)$.

Conclusion: Diclofenac improves the maintenance of per-operative mydriasis, in the presence of irrigating solutions containing adrenaline.
\end{abstract}

In small-incision surgery, safety and complication rate can be improved by maintenance of maximal pupillary dilation. This is of particular importance whilst learning the technique. Pre-operative mydriasis for cataract extraction is usually achieved by

From: ${ }^{1}$ Department of Ophthalmology, Queen Mary's Hospital Sidcup, Sidcup, Kent DA14 6LT, UK; ${ }^{2}$ Orpington Hospital, Sevenoaks Road, Orpington, Kent BR6 9JU, UK.

Correspondence to: D. R. Trew, FRCS, FRCOphth, Orpington Hospital, Sevenoaks Road, Orpington, Kent BR6 9JU, UK. application of a topical adrenergic agonist such as phenylephrine in combination with a cholinergic antagonist such as cyclopentolate. Adrenaline has been shown to help maintain mydriasis during extracapsular cataract surgery when used in irrigating solutions, by directly stimulating the dilator pupillae.

Surgical trauma during phacoemulsification, such as manipulation of the iris both mechanically and with irrigation solutions, leads to prostaglandin release and miosis. These reactions are independent of cholinergic and adrenergic receptors. ${ }^{2}$ Diclofenac sodium (diclofenac) is a powerful inhibitor of prostaglandin synthesis. Topical diclofenac has been shown to decrease cataract-induced blood-aqueous barrier breakdown. ${ }^{3}$ It has been shown to reduce surgically induced miosis in extracapsular surgery and in animal models. ${ }^{4-9}$ It has also been used to decrease pseudophakic cystoid macular oedema ${ }^{10}$ and post-operative inflammation without any increase in intraocular pressure. ${ }^{11-14}$

Many phacoemulsification units routinely use adrenaline in irrigating solutions. We investigated prospectively whether the use of topical diclofenac pre-operatively had any additional benefit in the presence of irrigating solutions containing adrenaline.

\section{PATIENTS AND METHODS}

Sixty-four consecutive patients due to undergo routine phacoemulsification were enrolled into the study. Patients with diabetes or a past history of inflammatory eye disease were excluded. Pre-operatively they were instilled with one drop of guttae phenylephrine $10 \%$ and cyclopentolate $1 \%$ four times. Patients. were randomised to receive either four doses of guttae diclofenac (Voltarol Ophtha) pre-operatively concurrently with their dilating drops, or no diclofenac. 
Patients then underwent routine phacoemulsification by one experienced consultant surgeon. This was done through a scleral tunnel, with implantation of a $5.5 \mathrm{~mm}$ optic (IOLAB). Hydroxymethylcellulose was used as a viscoelastic and irrigating solutions were balanced salt solution with adrenaline $1: 10^{6}$.

Horizontal pupil diameters were measured on a masked basis to the nearest $0.5 \mathrm{~mm}$ by callipers at set points during the surgery. These were pre-sclerostomy, post-phacoemulsification, post-infusion/aspiration (automated) and on day 1 with a Haag-Streit slit lamp.

The patient groups were analysed for sex and eye by chi-squared with Yates' correction and for age by Student's $t$-test. The pupil diameters were analysed by Student's $t$-test.

\section{RESULTS}

There were 32 patients in each group. Thirteen patients were male and 19 female in the diclofenac group and 7 were male and 25 were female in the no diclofenac group $(0.5<p<0.1)$. There were 15 right eyes and 17 left eyes in the diclofenac group and 19 right eyes and 13 left eyes in the no diclofenac group $(0.5<p<0.1)$. The mean age in the diclofenac group was 77 years (range 58-94 years) and the mean age was 75 years (range 54-92 years) in the no diclofenac group $(p=0.3)$. Four patients in the diclofenac group and 3 patients in the no diclofenac group were operated on under general anaesthetic. The remainder of the operations were all performed under local anaesthetic using peribulbar injections. There were no per-operative complications.

The mean pupillary diameters before the sclerostomies were $8.1 \mathrm{~mm}$ in both groups ( $p=0.7$ by $t$-test; Table I, Fig. 1). The mean diameters postphacoemulsification were $7.6 \mathrm{~mm}$ in the diclofenac group (range 6-9 $\mathrm{mm}$ ) and $7.2 \mathrm{~mm}$ in the no diclofenac group (range 5-8.5 mm). This difference of $0.4 \mathrm{~mm}$ was statistically significant $(p=0.03)$. The difference between mean diameters post-infusion/ aspiration was greater by $0.6 \mathrm{~mm}$, being $7.7 \mathrm{~mm}$ in the diclofenac group (range 6-9 $\mathrm{mm}$ ) and $7.1 \mathrm{~mm}$ in the no diclofenac group (range 5.5-8.5 mm). This was reflected in a greater statistical significance $(p=0.008)$. The mean diameters on day 1 were $5.3 \mathrm{~mm}$ (range $4-7 \mathrm{~mm}$ ) and $4.6 \mathrm{~mm}$ (range $3-7 \mathrm{~mm}$ ), again a difference of $0.6 \mathrm{~mm}(p=0.003)$.

Table I. Mean horizontal pupil diameters in millimetres during the surgery

\begin{tabular}{lcc}
\hline & No diclofenac & Diclofenac \\
\cline { 2 - 3 } Stage & & \\
\hline Pre-sclerostomy & 8.1 & 8.1 \\
Post-phacoemulsification & 7.2 & 7.6 \\
Post-infusion/aspiration & 7.1 & 7.7 \\
Day 1 post-surgery & 4.6 & 5.3 \\
\hline
\end{tabular}

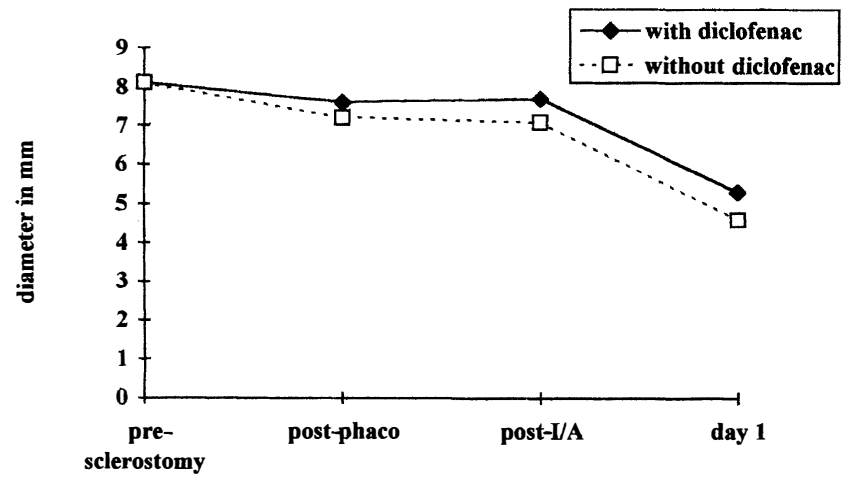

Fig. 1. Mean horizontal pupillary diameters during the surgery, with and without diclofenac sodium. I/A, infusion/ aspiration.

\section{DISCUSSION}

Activation of phospholipase $\mathrm{A}_{2}$ following tissue injury leads to the breakdown of cell membrane phospholipids to arachidonic acid. This is then converted to prostaglandins by cyclo-oxygenase, or to hydroxy acids and leukotrienes by 5-lipoxygenase. ${ }^{15}$ Cataract extraction is associated with increased prostaglandin levels in the aqueous. ${ }^{16}$ Surgery also leads to protein influx into the anterior chamber due to breakdown of the blood-aqueous barrier ${ }^{17}$ and miosis resistant to atropine. ${ }^{2}$ These changes are mediated in part by prostaglandins. Diclofenac reduces prostaglandin activity mainly by inhibition of cyclo-oxygenase. ${ }^{2}$

Diclofenac has been shown to be effective in maintaining mydriasis in rabbit models. ${ }^{4}$ Previous investigations in extracapsular cataract surgery in humans have shown variable results. ${ }^{5-9}$ In the absence of adrenaline two studies showed a significant benefit ${ }^{5-7}$ and two showed statistical but limited benefit. ${ }^{8,9}$ Our series, with an improvement of $0.6 \mathrm{~mm}$ at best, would confirm this limited benefit. However, no patients in either group had a pupillary diameter of less than $5 \mathrm{~mm}$ per-operatively - which previous authors have used as a surgically significant cut-off. ${ }^{1}$

The fact that any miosis occurs indicates either that prostaglandin synthesis has been incompletely blocked, or that other mechanisms which are too great to be overcome by adrenaline are present. Mediators that have been implicated include substance $\mathrm{P}^{18}$ and vasoactive intestinal polypeptide. ${ }^{19} \mathrm{To}$ fully prevent miosis during cataract surgery, further investigation of these factors is required. Careful cost-benefit analysis would be required, however, to confirm the clinical benefit of additional agents.

This study shows that in the presence of irrigating solutions containing adrenaline, topical diclofenac has a statistically significant but clinically small additive effect in maintaining per-operative mydriasis. 
Key words: Cataract, Surgery, Mydriasis.

\section{REFERENCES}

1. Corbett MC, Richards AB. Intraocular adrenaline maintains mydriasis during cataract surgery. $\mathrm{Br} \mathrm{J}$ Ophthalmol 1994;78:95-8.

2. Goa KL, Chrisp P. Ocular diclofenac: a review of its pharmacology and clinical use in cataract surgery, and potential in other inflammatory ocular conditions. Drugs Ageing 1992;2:473-86.

3. Araie M, Sawa M, Takase M. Topical flurbiprofen and diclofenac suppress blood-aqueous barrier breakdown in cataract surgery: a fluorophotometric study. Jpn J Ophthalmol 1983;27:535-42.

4. Bonomi L, Perfetti S, Bellucci R, Massa F, De Franco I. Prevention of surgically induced miosis by diclofenac eye drops. Ann Ophthalmol 1987;19:142-5.

5. Fabian E, von Denffer H, Wertheimer R. Diclofenac eye drops to maintain mydriasis during extracapsular cataract extraction. Ophthalmo-Chirurgie 1991;3: $115-9$.

6. Erturk H, Ozcetin H, Avci R. Diclofenac sodium for the prevention of surgically-induced miosis. Eur J Implant Refract Surg 1991;3:55-7.

7. Dimitrakos SA, Topouzidis C, Panidou-Kyriakidou I. Prevention du myosis peroperatoire: comparison des inhibitors de prostaglandins. Diclophenac sodium et indomethacine en application locale. J Fr Ophtalmol 1992;15:5-8.

8. Bonomi L, Totolo G, Marchini G, Rigotti P, Ghini M. Prevention of trauma-induced miosis during cataract surgery by diclofenac eye drops. New Trends Ophthalmol 1987;2:513-9.

9. Psilas K, Kalogeropoulos C, Loucatzicos E, Aspoudis I, Petroutsos G. The effect of indomethacin, diclofenac and flurbiprofen on the maintenance of mydriasis during extracapsular cataract extraction. Doc Ophthalmol 1992;81:293-300.

10. Quentin CD, Behrens-Baumann W, Gaus W. Prophylaxe des zystoiden Makulodems mit Diclofenac-Augen- trofen bei i.c. Kataraktextraktion mit Choyce-MarkIX-Vorderkammerlinse. Fortschr Ophthalmol 1989;86: 546-9.

11. Roberts CW, Brennan KM. A comparison of topical diclofenac with prednisolone for post-cataract inflammation. Arch Ophthalmol 1995;113:725-7.

12. Othenin-Girard P, Tritten JJ, Pittet N, Herbort CP. Dexamethasone versus diclofenac sodium eyedrops to treat inflammation after cataract surgery. J Cataract Refract Surg 1994;20:9-12.

13. Strelow SA, Sherwood MB, Broncato LJB, Napier A, Driebe WT, Guy JR, Vickers FF, Mellars K. The effect of diclofenac sodium ophthalmic solution on intraocular pressure following cataract extraction. Ophthalmic Surg 1992;23:170-5.

14. Kraff MC, Martin RG, Neumann AC, Weinstein AJ. Efficacy of diclofenac sodium ophthalmic solution versus placebo in reducing inflammation following cataract extraction and posterior chamber lens implantation. J Cataract Refract Surg 1994;20:138-44.

15. Flower R. Glucocorticoids, phospholipase $\mathrm{A}_{2}$ and inflammation. Pharmacol Sci 1981;2:186-9.

16. Miyake K, Sugiyama S, Norimatsu I, Ozawa T. Prevention of cystoid macular oedema after lens extraction by topical indomethacin. III. Radioimmunoassay measurements of prostaglandins in the aqueous during and after lens extraction procedures. Graefes Arch Klin Exp Ophthalmol 1978;209:83-8.

17. Sawa M, Araie M, Tanishima T. Fluorophotometric study of the barrier functions in the anterior segment of the eye after intracapsular cataract surgery. Jpn J Ophthalmol 1983;27:404-15.

18. Soloway MR, Stjernschantz J, Saers M. The miotic effect of substance P on the isolated rabbit iris. Invest Ophthalmol Vis Sci 1981;20:46-52.

19. Uddman R, Alumets J, Ehringer B, Hakenson R, Loren I, Sundler F. Vasoactive intestinal peptide nerves in ocular and orbital structures of the cat. Invest Ophthalmol Vis Sci 1980;19:878-85. 